\title{
Response of atrial flutter to overdrive atrial pacing and intravenous disopyramide phosphate, singly and in combination
}

\author{
JOHN CAMM, DAVID WARD, ROWORTH SPURRELL \\ From the Department of Cardiology, St Bartholomew's Hospital, London
}

SUMMARY Ten patients who suffered spontaneous paroxysms of atrial flutter were investigated by electrophysiological techniques. Two had overt Wolff-Parkinson-White syndrome; three LownGanong-Levine syndrome; and one a concealed accessory atrioventricular connection. Atrial flutter was initiated, at study, by right atrial pacing and electrograms from the right atrium and coronary sinus were observed for at least five minutes to ensure stable flutter in both atria.

Atrial flutter was terminated by $2.5 \mathrm{~s}$ or $5 \mathrm{~s}$ bursts of atrial pacing at rates 10,50 , or $100 \mathrm{beats} / \mathrm{min}$ faster than the intrinsic flutter rate in only two patients. Atrial flutter, which was reinitiated in two patients, was then treated with intravenous disopyramide phosphate, $2 \mathrm{mg} / \mathrm{kg}$ body weight, infused over five minutes. In all 10 patients the atrial rate slowed from a mean of $310 \pm 39$ beats $/ \mathrm{min}$ to $217 \pm 27$ beats/min and atrial flutter terminated in one case. Though the mean ventricular rate fell from $161 \pm 52$ beats/min to $156 \pm 45$ beats/min the atrioventricular conduction ratio fell from $2 \cdot 17 \pm 0.86$ to $1 \cdot 55 \pm 0.59$ and four patients were left with symptomatically significant increases of ventricular rate. In seven of nine patients overdrive atrial pacing, repeated after disopyramide, resulted in the conversion of atrial flutter to sinus rhythm.

In this study, overdrive atrial pacing and intravenous disopyramide, singly and in combination, terminated atrial flutter in nine of the 10 patients and it is suggested that this method may provide an effective alternative to direct current cardioversion.

In 1967, Haft and coworkers ${ }^{1}$ reported the successful termination of atrial flutter by rapid atrial pacing. They also suggested that premedication with quinidine-like drugs potentiated the success of the technique. Though others ${ }^{2-11}$ have used atrial pacing techniques to treat atrial flutter with variable and, at times, contradictory results ${ }^{12} 13$ little attention has been given to pretreatment with antiarrhythmic agents. Here we report the individual and combined results of overdrive atrial pacing and intravenous disopyramide phosphate in the treatment of paroxysms of atrial flutter.

\section{Subjects and methods}

Ten patients aged between 22 and 62 years were investigated for complaints of recurrent paroxysmal palpitations (Table 1). All patients had suffered documented attacks of atrial flutter and three patients also had attacks of "supraventricular" Received for publication 18 February 1980 tachycardia which were not thought to be atrial flutter. One patient presented with profound sinus bradycardia, sinus node arrest, and paroxysms of tachycardia. There was no clinical or radiographic evidence of organic heart disease though two patients were mildly hypertensive. The surface electrocardiogram was normal in four patients, showed sinus bradycardia in one, and a short PR interval in five. In two patients, the short PR interval was followed by broad QRS complexes of the Wolff-Parkinson-White pattern, type A. Routine blood tests, including thyroid function tests, were normal in all patients.

The patients underwent intracardiac electrophysiological investigation in the catheterisation laboratory or coronary care unit. All patients were studied in a fasting unsedated state and had not received medication for at least 72 hours before the study. Informed consent was obtained from each patient. Conventional electrophysiological investigations were performed as described elsewhere, ${ }^{14}$ 
but for the purpose of this study bipolar electrodes were positioned to record simultaneously or sequentially from the lateral wall of the right atrium (close to its junction with the superior vena cava) and the coronary sinus. Atrial flutter was initiated by rapid atrial pacing and the arrhythmia was observed for five minutes to ensure that there was stable flutter of both atria. At the end of this period, attempts were made to terminate atrial flutter by atrial pacing from the single right atrial site at a stimulus voltage of twice the diastolic threshold during sinus rhythm. Pacing rates were adjusted to 10,50 , and 100 beats/min faster than the spontaneous flutter rate and pacing was continued for periods of two and a half and five seconds. If this resulted in the successful termination of the arrhythmias, atrial flutter was restimulated and reobserved for a further five minutes to ensure stability. Disopyramide phosphate, at a dose of $2 \mathrm{mg} / \mathrm{kg}$ body weight, was then administered to all 10 patients. The infusion was given evenly over exactly five minutes, and continuous electrocardiographic recordings at a paper speed of $25 \mathrm{~mm} / \mathrm{s}$ were made for a period of 10 minutes. Short strips were recorded at $100 \mathrm{~mm} / \mathrm{s}$ at one minute intervals.

If atrial flutter had not terminated in response to disopyramide within 10 minutes of the start of the infusion, rapid atrial pacing for durations of two and a half and five seconds, at rates 10, 50, and 100 beats/min faster than the new flutter frequency, was again tried.

Atrial and ventricular rates were measured at one minute intervals throughout the study. Where the ventricular rate was irregular, the mean rate over a 10 second period was calculated. The atrioventricular conduction ratios were derived from these values. The maximum ventricular rate during the study period was noted. Results were analysed by the paired Student's t test.
Table 1 Clinical, electrocardiographic, and electrophysiological details of 10 patients with recurrent paroxysmal atrial flutter

\begin{tabular}{rllll}
\hline $\begin{array}{l}\text { Case } \\
\text { no. }\end{array}$ & $\begin{array}{l}\text { Age }(y) \cdot \\
\text { sex }\end{array}$ & Diagnosis & EPS \\
\hline 1 & 31 & M & PAFl, SVT, LGL & PAFl, AVRT(CLAP) \\
2 & 44 & M & PAFl & PAFl \\
3 & 39 & F & PAFl, SAD, LGL & PAFl, SAD \\
4 & 62 & M & PAFl, LGL & PAFl \\
5 & 22 & F & PAFl & PAFl \\
6 & 58 & M & PAFl & PAFl \\
7 & 48 & M & PAFl & PAFl \\
8 & 62 & M & PAFl, SVT, WPW & PAFl, AVRT(LAP) \\
9 & 48 & M & PAFl, SVT, WPW & PAFl, AVRT(LAP) \\
10 & 52 & M & PAFl & PAFl \\
\hline
\end{tabular}

PAFl, paroxysmal atrial flutter; SVT, supraventricular tachycardia; LGL, Lown-Ganong-Levine syndrome; SAD, sinuatrial disease ; WPW, Wolff-Parkinson-White syndrome; AVRT, atrioventricular re-entrant tachycardia; CLAP, concealed left-sided accessory pathway; LAP, left-sided accessory pathway; EPS, electrophysioogical study diagnosis.

\section{Results}

The results of routine electrophysiological studies in the 10 patients are summarised in Table 1 . In six patients, no electrophysiological abnormality could be detected, but in one, abnormal sinus node function was documented and, in three, left-sided accessory atrioventricular pathways were disclosed and re-entrant tachycardias, using these pathways in the retrograde direction, were precipitated.

In all 10 patients, stable atrial flutter of both chambers was initiated by atrial pacing. The initial flutter frequency, the ventricular response rate, and the atrioventricular ratio are set out in Table 2, and illustrated in Fig. 1 and 2. The flutter rate varied between 230 beats/min and 375 beats $/ \mathrm{min}$ (mean $=310 \pm 39$ beats $/ \mathrm{min}$ ), and in eight cases characteristic "saw tooth" flutter waves were seen, but, in two, both with overt Wolff-ParkinsonWhite syndrome, baseline oscillations were obscured

Table 2 Response of atrial flutter to disopyramide (diso) and overdrive atrial pacing (RAP)

\begin{tabular}{|c|c|c|c|c|c|c|c|c|c|c|}
\hline \multirow{2}{*}{$\begin{array}{l}\text { Case } \\
\text { no. }\end{array}$} & \multicolumn{2}{|c|}{ Atrial rate } & \multicolumn{3}{|c|}{ Ventricular rate } & \multicolumn{2}{|c|}{$A / V$ ratio } & \multicolumn{3}{|c|}{ Termination } \\
\hline & Pre & Post & Pre & $\operatorname{Max}$ & Post & Pre & Post & Diso & $R A P($ pre $)$ & $R A P($ post $)$ \\
\hline 1 & 320 & 220 & 130 & 171 & 130 & $2 \cdot 46$ & 1.69 & 0 & 0 & t. \\
\hline 2 & 353 & 230 & 86 & 110 & 90 & $4 \cdot 10$ & 2.55 & + & 0 & NR \\
\hline 3 & 300 & 176 & 150 & 220 & 176 & $2 \cdot 00$ & $1 \cdot 00$ & 0 & 0 & t- \\
\hline 4 & 336 & 264 & 156 & 156 & 138 & $2 \cdot 15$ & 1.91 & 0 & + & 0 \\
\hline 5 & 328 & 256 & 164 & 164 & 128 & $2 \cdot 00$ & $2 \cdot 00$ & 0 & + & + \\
\hline 7 & 280 & 210 & 140 & 210 & 210 & 2.00 & 1.00 & 0 & 0 & + \\
\hline 8 & 230 & 188 & 230 & 230 & 188 & 1.00 & $1 \cdot 00$ & 0 & 0 & + \\
\hline 9 & 280 & 194 & 280 & 280 & 194 & 1.00 & $1 \cdot 00$ & 0 & 0 & + \\
\hline 10 & 300 & 220 & 150 & 220 & 220 & $2 \cdot 00$ & 1.00 & 0 & 0 & + \\
\hline Mean & 310 & 217 & 161 & 189 & 156 & $2 \cdot 17$ & 1.55 & & & \\
\hline $\operatorname{SD}( \pm)$ & 39 & 27 & 52 & 49 & 45 & 0.86 & 0.59 & & & \\
\hline
\end{tabular}

pre, pre-disopyramide; post, post-disopyramide; $\max$, maximum ventricular rate observed during 10-minute observation period after the start of the disopyramide infusion; + , successful conversion; 0 , unsuccessful conversion; NR, not relevant. 

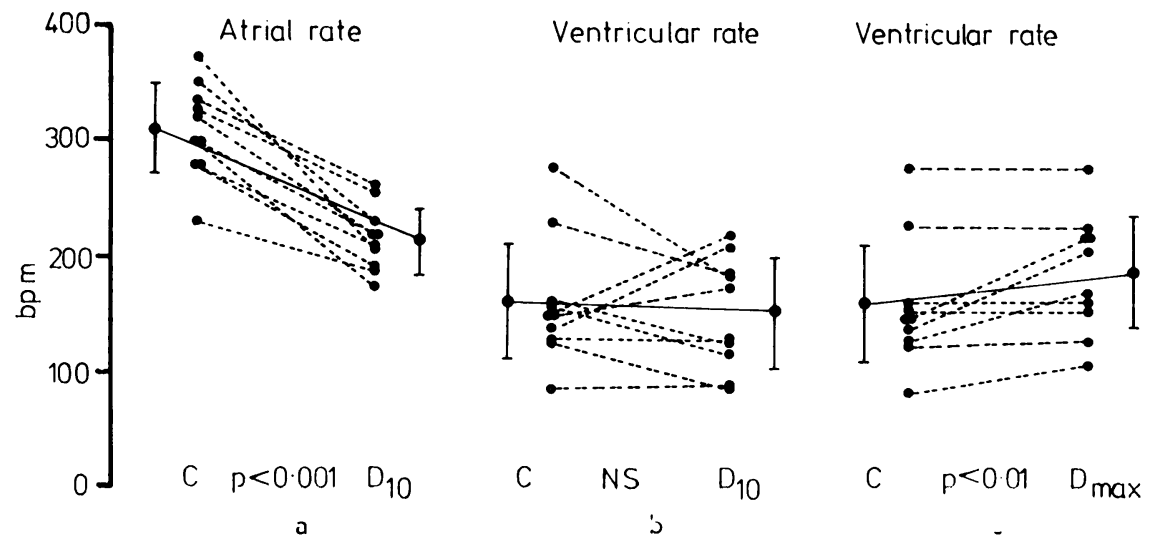

Fig. 1 Atrial and ventricular rates before and after disopyramide infusion. C, control; $D_{10}, 10$ minutes after disopyramide; $D_{\max }$, maximum ventricular rate during the 10 minute observation period after the start of the disopyramide infusion; bpm, beats per minute.

by $1: 1$ conduction over the accessory pathway.

Rapid atrial pacing, before disopyramide (Fig. 3) successfully terminated two examples of atrial flutter (cases 4 and 5 ). In the remainder, flutter was entrained (six cases) or atrial capture was not achieved (two cases).

The infusion of disopyramide phosphate resulted in reduction of the atrial rate in all patients. The mean atrial rate fell significantly $(p<0.001)$ from $310 \pm 39$ beats/min to $217 \pm 27$ beats/min (Fig. 1a). In one patient atrial flutter terminated six minutes after the start of the disopyramide infusion. The ventricular rate response to disopyramide infusion was variable. Fig. 4 illustrates the response in case 9. Initially, the atrioventricular rate was 280 beats/min, and five minutes after the conclusion of the disopyramide infusion the $1: 1$ atrioventricular relation persisted at a rate of 194 beats/min. In case 7 (Fig. 5) 2:1 atrioventricular conduction was present initially but, in response to disopyramide, the atrial rate slowed from 270 beats/min to 200 beats/min with the development of $1: 1$ atrioventricular conduction. Results in the 10 patients are illustrated in Fig. 6 and are demonstrated graphically in Fig. $1 \mathrm{~b}$ and $1 \mathrm{c}$. In six patients, the ventricular rate increased at some time during the 10 minute observation period (Fig. 1c) and the mean increase $(161 \pm 52$ to $189 \pm 49$ beats $/ \mathrm{min})$ was significant $(\mathrm{p}<0.01)$. By the end of the observation period (Fig. 1b) there was an insignificant fall in the mean ventricular rate ( $161 \pm 57$ to $156 \pm 45$ beats $/ \mathrm{min}$ ), but the atrioventricular conduction ratio had significantly $(p<0.01)$ fallen $(2.17 \pm 0.86$ to $1.55 \pm 0.59)$.

In nine patients, the termination of the arrhythmia by overdrive atrial pacing was attempted again after the infusion of disopyramide. The technique proved successful in seven cases, six of whom had not responded before disopyramide. In the two failures it was not possible to achieve atrial capture. In the successful cases, atrial pacing usually resulted in transient runs of atrial tachycardia or fibrillation before conversion to sinus rhythm. Atrial fibrillation of a duration longer than $5 \mathrm{~s}$ was not precipitated except in the two failures, who after completing the study were subjected to longer and faster periods of atrial pacing. One of these patients eventually required direct current cardioversion. The overall results of the combined technique are illustrated in Fig. 7.

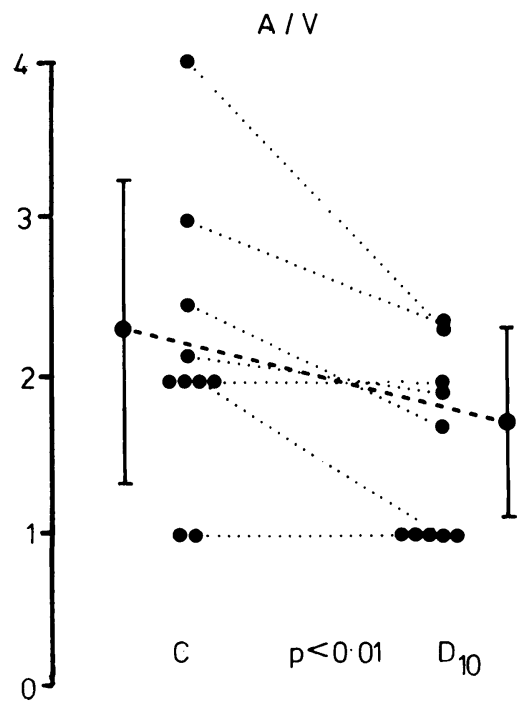

Fig. 2 The atrioventricular $(A / V)$ ratio before $(C)$ and after $\left(D_{10}\right)$ disopyramide infusion. 


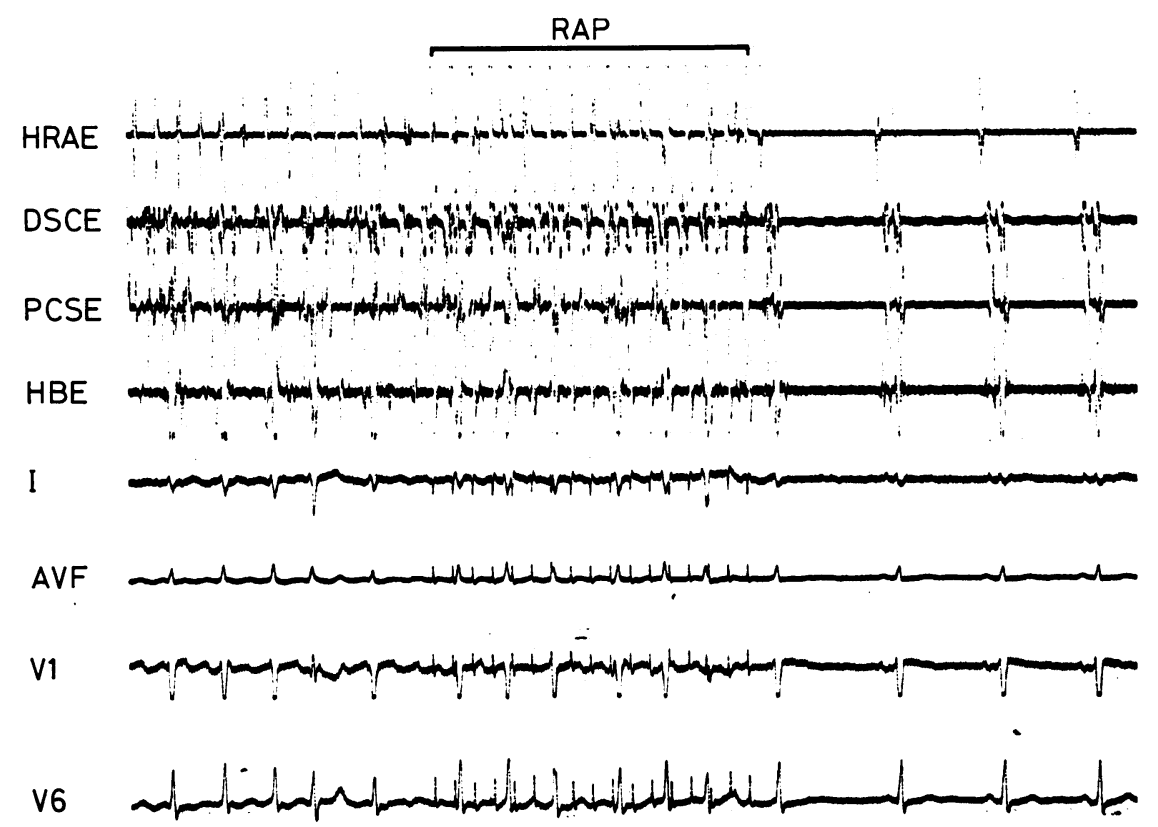

Fig. 3 The successful conversion of atrial flutter by rapid atrial pacing before the administration of disopyramide (case 4). The atrial flutter rate is 336 beats/min; the average ventricular rate is 156 beats/min; and the atrial pacing rate is 386 beats/min for 2.5 seconds.

$H R A E$, high right atrial electrogram; DCSE, distal coronary sinus electrogram; PCSE, proximal coronary sinus electrogram; HBE, His bundle region electrogram; $R A P$, rapid atrial pacing; $1, a V F, V 1$, and V6 are surface electrocardiogram leads; paper speed, $25 \mathrm{~mm} / \mathrm{s}$.

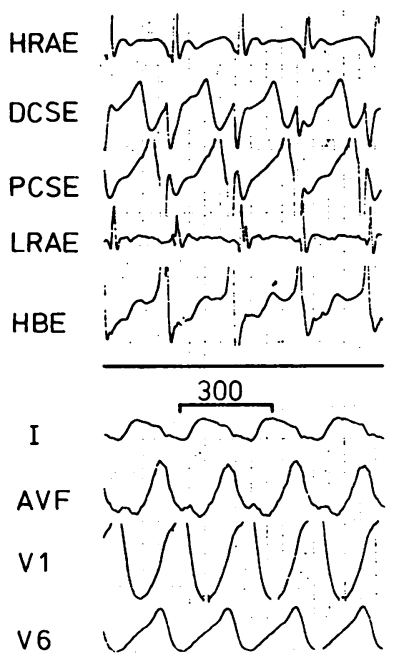

A
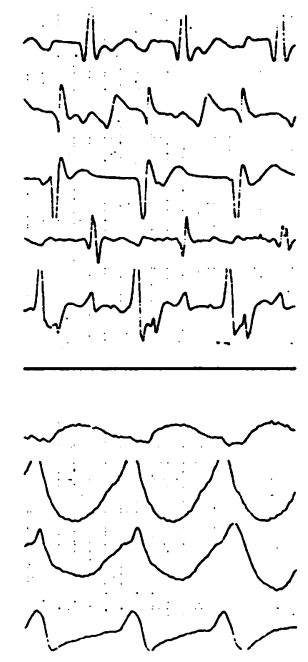

B

Fig. 4 Atrial flutter with $1: 1 \mathrm{AV}$ conduction via a left-sided accessory atrioventricular pathway before and 10 minutes after the infusion of disopyramide. The rate falls from 280 beats/min to 194 beats/min (case 9). LRAE, low right atrial electrogram. Paper speed, $100 \mathrm{~mm} / \mathrm{s}$.

\section{Discussion}

In 1963, Moe et al. ${ }^{15}$ showed that paced atrial extrastimulation could interrupt experimental reciprocating atrioventricular nodal tachycardia, and recently Wit and Cranefield ${ }^{16}$ showed that triggered tachycardias would also stop in response to premature stimulation. Massumi et al. ${ }^{17}$ first applied artificial pacing methods to the treatment of supraventricular tachycardia, and Durrer and colleagues ${ }^{18}$ confirmed these clinical results and stressed that the termination of tachycardia by premature beats required critical timing. When a single premature beat will suffice it may be simply provided by fixed rate underdrive pacing, ${ }^{11}$ but if several depolarisations are required, overdrive pacing may be necessary. The termination of supraventricular tachycardia by overdrive atrial pacing was first reported in $1968^{19}$; by 1972 , it was an accepted alternative to direct current cardioversion, ${ }^{20}$ and it is now recognised as a very successful method for the termination of the majority of supraventricular tachycardias. ${ }^{21}$

Since the report by Haft et al. in $1967,{ }^{1}$ other investigators have confirmed that atrial flutter may be successfully converted to sinus rhythm by over- 
drive atrial pacing, but there have been several dissenting reports. Puech et al. ${ }^{12}$ succeeded in terminating immediately only six of 29 cases of atrial flutter and in 22 atrial fibrillation was the result. In six of these, however, the atrial fibrillation lasted only a few seconds. Rosen and colleagues ${ }^{13}$ treated 15 cases by overdrive atrial pacing: none reverted to sinus rhythm, but "stable" atrial fibrillation was induced in six patients. Our results were similarly poor before the administration of disopyramide. The poor results are probably a result of limiting the duration of pacing, the pacing rate, and the pacing energy. These limitations, which have not specifically been applied by others, were designed to minimise the risk of precipitating atrial fibrillation which did not occur in this series.

Disopyramide phosphate, a butyramide derivative, has been shown to reduce the frequency of automatically discharging foci and to slow the conduction velocity in both myocardial and specialised conduction tissue. ${ }^{22} 23$ In addition to its membrane stabilising effect disopyramide increases the duration of the action potential ${ }^{23}$ and, in man, may prolong the atrial refractory period. ${ }^{24}{ }^{25}$ Though the mechanism of atrial flutter is controversial, ${ }^{26}$ some suggesting that abnormal automaticity ${ }^{27}{ }^{28}$ is the cause and others preferring a re-entrant basis, ${ }^{29-31}$ whichever the mechanism the electrophysiological properties of disopyramide could explain both the termination and the slowing of atrial flutter. If circus movement sustains the arrhythmia decreased atrial conduction velocity would lead to slowing of the flutter rate but, if atrial refractoriness increased sufficiently to exceed the tachycardia cycle length, the arrhythmia would be extinguished. Alternatively, the depressant effect of disopyramide on spontaneous diastolic depolarisation would result in slowing, and possibly termination of atrial flutter caused by enhanced atrial automaticity. Decreased atrial excitability ${ }^{32}$ induced by disopyramide may also contribute to the termination of atrial flutter.

The effect of disopyramide on atrial flutter has not been reported in detail. Though Luoma et al. ${ }^{33}$ studied patients with atrial flutter, they did not distinguish this arrhythmia from atrial fibrillation. In the cases reported by Vandenbosch et al., ${ }^{34}$ disopyramide converted three of 11 examples of atrial flutter and, in the series of Deano et al., ${ }^{35}$ three of eight patients reverted to sinus rhythm in response to disopyramide. Our rate of success with conversion was comparatively low and while this may be partly related to the short observation period, previous experience with intravenous disopyramide indicated that the majority of terminations occurred within 10 minutes of the start of the infusion ${ }^{36}$ and, in any event, it is difficult to ascribe late terminations to the action of the drug. ${ }^{37}$

In this series, as in others, ${ }^{34}{ }^{35}$ disopyramide resulted in consistent and pronounced slowing of the atrial flutter frequency. In the presence of $1: 1$ atrioventricular conduction, the ventricular rate also slowed, but when a degree of atrioventricular conduction block was present, the infusion

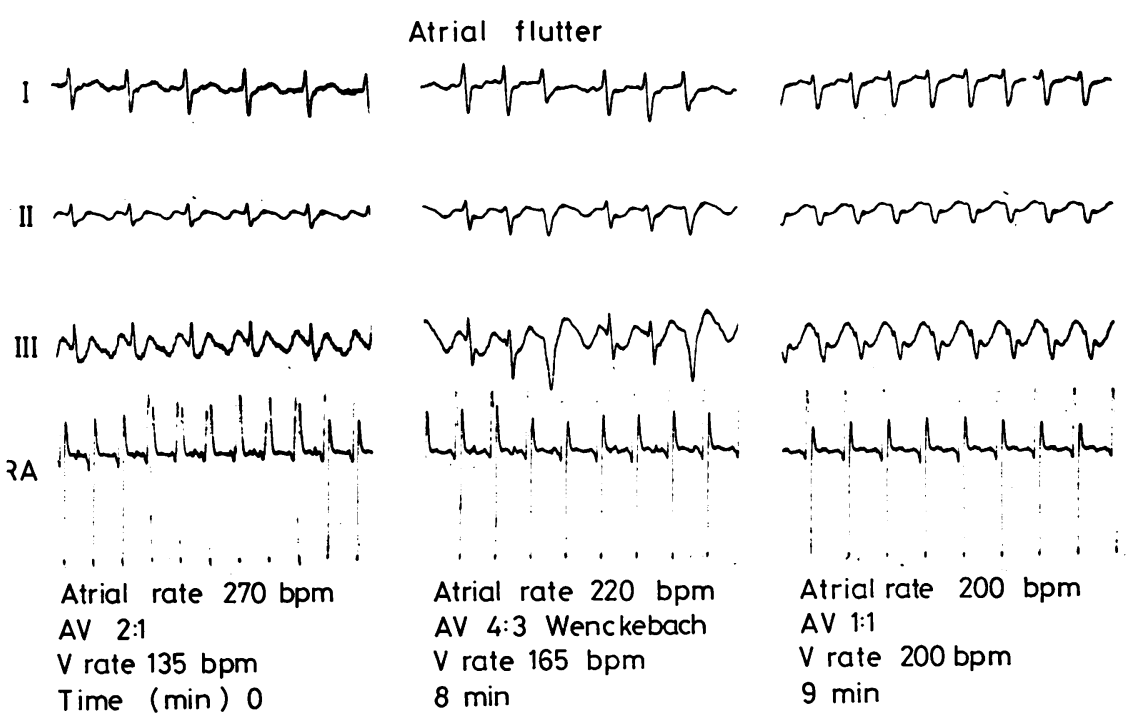

Fig. 5 Atrial flutter before (0) and 8 and 9 minutes after the infusion of disopyramide (case 7). See text for discussion. I, II, III are surface electrocardiogram leads. RA, right atrial electrogram. Paper speed, $25 \mathrm{~mm} / \mathrm{s}$. 
of disopyramide resulted in higher ventricular rates in six cases. This result is a potential hazard when treating atrial flutter with disopyramide, and represents the combined effects of slowing of flutter frequency and anticholinergic effects on the atrio-
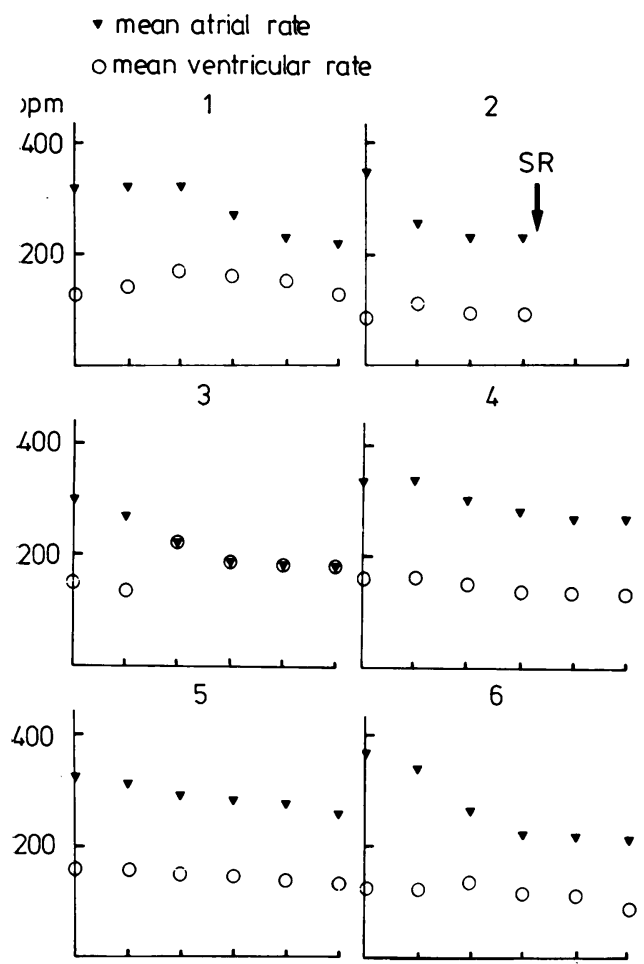

7
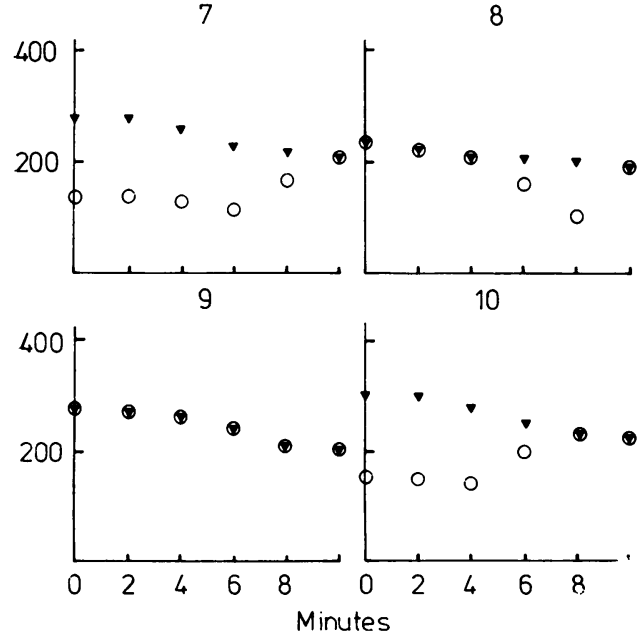

Fig. 6 Atrial and ventricular responses at $0,2,4,6,8$, and 10 minutes, after disopyramide infusion in cases 1 to 10.

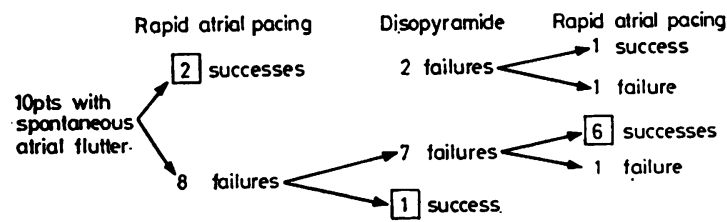

Fig. 7 Successful and unsuccessful conversion to sinus rhythm in 10 cases of atrial flutter.

ventricular node. ${ }^{25} 3839$ When $1: 1$ atrioventricular conduction occurs after the treatment of atrial flutter with disopyramide the flutter frequency is considerably less than the pretreatment rate and very rapid ventricular rates do not result. Nevertheless, if disopyramide does not achieve conversion of atrial flutter to sinus rhythm the combination of increased ventricular rates and depressed myocardial function could lead to significant symptomatic deterioration and systemic hypotension. This serious side effect was not encountered in this study. Similar effects have been observed with quinidine ${ }^{40-42}$ and procainamide. ${ }^{43}$

The possibility that premedication with a quinidine-like antiarrhythmic agent would potentiate the conversion of atrial flutter to sinus rhythm by overdrive atrial pacing was suggested by Haft et al. ${ }^{1}$ In one of their cases, rapid atrial pacing was effective only after administration of oral procainamide. In a recent report by Wyndham et al. ${ }^{44}$ pretreatment with disopyramide reduced the risk of atrial pacing precipitating atrial fibrillation and improved the chances of successful conversion of atrial flutter to sinus rhythm.

This study has attempted to assess systematically the value of premedication of atrial flutter with disopyramide before overdrive atrial pacing, and the results suggest that the conversion rate to sinus rhythm is improved. If atrial flutter were a result of circus movement, an increase of atrial refractoriness after disopyramide might increase the physiological obstacle around which the flutter wavelet circulated ${ }^{45}$ allowing pacing closer to an enlarged circuit. Alternatively, if conduction slowed without a commensurate increase of refractoriness the excitable gap between the tachycardia depolarisation wavefront and its receding repolarised tail would increase. Either result would facilitate the invasion and "saturation" of the tachycardia circuit by pacemaker-induced depolarisation. On the other hand, if flutter were the result of abnormal automaticity, a disopyramide-induced reduction in the discharge rate would improve the electrophysiological access to the focus of the arrhythmia, unless disopyramide produced conspicuous increases in atrial refractoriness or conduction times. 
Paroxysmal atrial flutter is difficult to treat effectively. Medical conversion of an individual paroxysm with drugs such as verapamil, ${ }^{46}$ betablockers, ${ }^{47}$ quinidine, ${ }^{41}$ and disopyramide, ${ }^{34-36}$ is generally disappointing and though synchronised direct current countershock is undoubtedly effective, ${ }^{48}$ it is not without risk. ${ }^{49}{ }^{50} \mathrm{~A}$ pacing method of terminating recurrent supraventricular arrhythmias has obvious attraction because it can be repeated often and may be adapted for long term use. Failure to achieve sinus rhythm and the unwanted precipitation of atrial fibrillation are the two main disadvantages of overdrive atrial pacing for the treatment of paroxysmal atrial flutter. Though the incidence of atrial fibrillation can be minimised by limiting the duration of pacing, the pacing frequency, and the pacing energy, the successful conversion rate of this arrhythmia to sinus rhythm is also reduced by these limitations. Premedication of atrial flutter with disopyramide restores the effectiveness of limited overdrive atrial pacing without increasing the risk of atrial fibrillation.

\section{References}

1 Haft JI, Kosowsky BD, Lau SH, Stein E, Damato AN. Termination of atrial flutter by rapid electrical pacing of the atrium. $A m \mathcal{F}$ Cardiol 1967; $20: 239-44$.

2 Zeft HJ, Cobb FR, Waxman MB, Hunt NC, Morris JJ Jr. Right atrial stimulation in the treatment of atrial flutter. Ann Intern Med 1969; 70: 447-56.

3 Gulotta SJ, Aronson AL. Cardioversion of atrial tachycardia and flutter by atrial stimulation. $A m \mathcal{F}$ Cardiol 1970; 26: 262-9.

4 Pittman DE, Makar JS, Kooros KS, Joyner CR. Rapid atrial stimulation: successful method of conversion of atrial flutter and atrial tachycardia. Am $\mathcal{F}$ Cardiol 1973; 32: 700-6.

5 Cheng TO. Atrial pacing: its diagnostic and therapeutic applications. Prog Cardiovasc Dis 1971; 14: 230-47.

6 Cheng TO. Rapid atrial pacing in treatment of atrial flutter and atrial tachycardia (abstract). Clin Res $1971 ; 19$ : 307.

7 Cheng TO. Rapid atrial pacing in conversion of atrial flutter (letter). Am F Cardiol 1973; 31: 287.

8 Pittman DE, Gay TC, Patel II, Joyner CR. Termination of atrial flutter and atrial tachycardia with rapid atrial stimulation. Angiology 1975; 26: 784-801.

9 Orlando J, Cassidy J, Aronow WS. High reversion of atrial flutter to sinus rhythm after atrial pacing in patients with pulmonary disease. Chest $1977 ; 71$ : $580-2$.

10 Waldo AL, MacLean WAH, Karp RB, Kouchoukos NT, James TN. Entrainment and interruption of atrial flutter with atrial pacing-studies in man following open heart surgery. Circulation 1977; 56: 737-45.

11 Hunt NC, Cobb FR, Waxman MB, Zeft HJ, Peter RH, Morris JJ Jr. Conversion of supraventricular tachycardias with atrial stimulation-evidence for re-entry mechanism. Circulation 1968; 38: 1060-5.

12 Puech P, Grolleau R, Latour H, Cabasson J, Robin JM, Baissus C. Traitement du flutter auriculaire par la stimulation auriculaire endocavitaire. Arch Mal Coeur 1973; 66: 159-67.

13 Rosen KM, Sinno MZ, Gunnar RM, Rahimtoola $\mathrm{SH}$. Failure of rapid atrial pacing in the conversion of atrial flutter. Am $\mathcal{F}$ Cardiol 1972; 29: 524-8.

14 Camm AJ, Ward DE, Spurrell RAJ. Gaps in anterograde conduction in patients with the short PR interval, normal QRS complex syndrome. Br Heart $\mathcal{F}$ 1978; 40: 1119-26.

15 Moe GK, Cohen W, Vick RL. Experimentally induced paroxysmal AV nodal tachycardia in the dog: a case report. Am Heart f 1963; 65: 87-92.

16 Wit AL, Cranefield PF. Triggered activity in cardiac muscle fibers of the simian mitral valve Circ Res 1976; 38: 85-98.

17 Massumi RA, Kistin AD, Tawakkol AA. Termination of reciprocating tachycardia by atrial stimulation. Circulation 1967; 36: 637-43.

18 Durrer D, Schoo L, Schuilenburg RM, Wellens HJJ. The role of premature beats in the initiation and the termination of supraventricular tachycardia in the Wolff-Parkinson-White syndrome. Circulation 1967; 36: 644-62.

19 Lister JW, Cohen LS, Bernstein WH, Samet P. Treatment of supraventricular tachycardias by rapid atrial stimulation. Circulation 1968; 38: 1044-59.

20 Vergara GS, Hildner FJ, Schoenfeld CB, Javier RP, Cohen LS, Samet P. Conversion of supraventricular tachycardias with rapid atrial stimulation. Circulation 1972; 46: 788-93.

21 Ward D, Camm J, Spurrell RAJ. The response of regular re-entrant supraventricular tachycardias to right heart stimulation. Pace 1979; 2: 586-95.

22 Sasyniuk BI, Kus T. Cellular electrophysiologic changes induced by disopyramide phosphate in normal and infarcted hearts. F Int Med Res 1976; 4, suppl 1:20-5.

23 Sekiya A, Vaughan-Williams EM. A comparison of the antifibrillatory actions and effects of intracellular cardiac potentials of pronethalol, disopyramide and quinidine. $\mathrm{Br}$ F Pharmacol 1963; 21 : 473-81.

24 Spurrell RAJ, Thorburn C, Camm J, Sowton E, Deuchar DC. Effects of disopyramide on electrophysiological properties of specialized conduction system in man, and on accessory atrioventricular pathway in Wolff-Parkinson-White syndrome. $B r$ Heart f 1975; 37: 861-7.

25 Birkhead JS, Vaughan-Williams EM. Dual effect of disopyramide on atrial and atrioventricular conduction and refractory periods. $\mathrm{Br}$ Heart $\mathcal{f} 1977 ; 39$ : 657-60.

26 Scherf $D$. The mechanism of flutter and fibrillation. Am Heart f 1966; 71: 273-80. 
27 Marques MG, Mota JCB, Nogueria RA. The mechanism of atrial flutter. Cardiologia 1962; 40: 269-80.

28 Prinzmetal M, Goldman A, Gerlach E, Kennamer R. Nature of spontaneous auricular flutter in man. f $A M A$ 1953; 153: 553-5.

29 Lewis T, Drury AN, Iliescu CC. A demonstration of circus movement in clinical flutter of the auricles. Heart 1921 ; 8: 341-55.

30 Rosenblueth A, Garcia Ramos J. Studies on flutter and fibrillation. 2. The influence of artificial obstacles on experimental auricular flutter. Am Heart $\mathcal{F} 1947$; 33: $677-84$.

31 Rytand DA. The circus movement (entrapped circuit wave) hypothesis and atrial flutter. Ann Intern Med 1966; 65: 125-59.

32 Gough W, Dreifus LS, de Azevado IM, Katz MR. Refractoriness of cardiac tissue. Cardiovasc Clin $1974 ; 6 / 1$ : 87-97.

33 Luoma PV, Kujala PA, Juustila HJ, Takkunen JT. Efficacy of intravenous disopyramide in the termination of supraventricular arrhythmias. $\mathcal{f}$ Clin Pharmacol 1978; 18: 293-301.

34 Vandenbosch R, Lisin N, Andriange M, Gach J, Carlier J. Experimentation clinique du disopyramide administre par voie intravineuse. Acta Cardiol (Brux) 1975; 30: 267-78.

35 Deano DA, Wu D, Mautner RK, Sherman RH, Ehsani AE, Rosen KM. The antiarrhythmic efficacy of intravenous therapy with disopyramide phosphate. Chest 1977; 71: 597-606.

36 Camm J, Ward D, Spurrell RAJ. The effect of intravenous disopyramide phosphate on recurrent paroxysmal tachycardias. Br $\mathcal{F}$ Clin Pharmacol 1979; 8: 441-9.

37 Hill I. Fallacies in the clinical evaluation of antiarrhythmic drugs. In: Sandoe E, Flensted-Jensen E, Olesen KH, eds. Symposium on cardiac arrhythmias. Södertälje: AB Astra, 1970: 473-7.

38 Jequier $R$, Deraedt $R$, Plongeron $R$, Vannier $B$. Pharmacologie et toxicologie $d u$ disopyramide. Farmacologia e tossicologia della disopiramide. Minerva Med 1970; 61, suppl 71: 7-10.
39 Baines MW, Davies JE, Kellett DN, Munt PL. Some pharmacological effects of disopyramide and a metabolite. F Int Med Res 1976; 4, suppl 1: 5-7.

40 Lewis $T$. The mechanism and graphic registration of the heart beat. 3rd ed. London: Shaw \& Sons, 1925: 359-60.

41 Acierno LJ, Gubner R. Utility and limitations of intravenous quinidine in arrhythmias. Am Heart $\mathcal{f}$ $1951 ; 41$ : 733-41.

42 Brown BB. A study of factors related to effects of quinidine in experimental auricular flutter. Circulation 1952; 5: 864-9.

43 Miller G, Weinberg SL, Pick A. The effect of procaine amide (Pronestyl) in clinical auricular fibrillation and flutter. Circulation 1952; 6: 41-50.

44 Wyndham CR, Wu D, Denes P, Sugarman D, Levitsky S, Rosen KM. Self-initiated conversion of paroxysmal atrial flutter utilizing a radio-frequency pacemaker. Am f Cardiol 1978; 41 : 1119-22.

45 Lewis $\mathrm{T}$. The mechanism and graphic registration of the heart beat. 3rd ed. London: Shaw \& Sons, 1925: 322.

46 Schamroth L, Krikler DM, Garrett C. Immediate effects of intravenous verapamil in cardiac arrhythmias. Br Med f 1972; 1: 660-2.

47 Gianelly R, Griffin JR, Harrison DC. Propranolol in the treatment and prevention of cardiac arrhythmias. Ann Intern Med 1967; 66: 667-76.

48 Castellanos A Jr, Lemberg L, Gosselin A, Fonseca EJ. Evaluation of countershock treatment of atrial flutter. Arch Intern Med 1965; 115: 426-33.

49 Lown B, Kleiger R, Williams J. Cardioversion and digitalis drugs; changed threshold to electric shock in digitalized animals. Circ Res $1965 ; 17$ : 519-31.

50 Rabbino MD, Likoff W, Dreifus LS. Complications and limitations of direct current countershock. f $A M A$ 1964; 190: 417-20.

Requests for reprints to Dr John Camm, Department of Cardiology, St Bartholomew's Hospital, London EC1 7BE. 